\title{
Mood States are Not Associated with BMI in Mentally Healthy Adults
}

\author{
Charles Halloran van Wijk \\ Private practice Simon's Town, South Africa \\ Email: Charles van Wijk; chvanwijk@gmail.com \\ Received April 28 $8^{\text {th }}, 2011$; revised June $7^{\text {th }}, 2011$; accepted July $16^{\text {th }}, 2011$.
}

\begin{abstract}
The relationship between Body Mass Index (BMI) and mental health has been widely investigated, and recent evidence has shown that overweight and obese individuals may be more vulnerable to the development of anxiety and mood disorders than individuals of a normal weight. This article examines the association between BMI and mood states of mentally healthy adults. BMI and Brunel Mood Scale (BRUMS) scores, and other demographic information, was collected from healthy adults over a six month period $(\mathrm{N}=1621)$. When age was controlled, only a small but significant negative correlation between BMI and Depression in men was found, which stands in contrasts to previous studies. This may be due to the sample of mentally healthy adults with less incidence of severe obesity due to their military background. Further, African samples may have different expressions for non-clinical distress than industrialised countries which may lead to skewed results. The findings suggests that measures of transient mood states, like the BRUMS, may not be particularly useful in investigating relationships between mental health constructs and anthropometric measures, like BMI.
\end{abstract}

Keywords: BMI, BRUMS, Mental Health, Mood States, Obesity

\section{Introduction}

Body Mass Index (BMI) is a number calculated from a person's weight and height, and an effective method for population assessment of overweight and obesity (CDC, 2010). Its main importance lies in the relationship between body weight and disease and death (WHO, 1995), with overweight and obese individuals at increased risk for many diseases and health conditions (NIH, 1998). Within the South African (SA) context, the negative health consequences associated with increased BMI is also well described: obesity is associated with increasing risk of developing hypertension, coronary heart diseases, diabetes, stroke, and some forms of cancer in both Black and White African populations (Joubert et al., 2007; Kruger et al., 2001; Levitt et al., 1993; Steyn et al., 1996).

The relationship between BMI and mental health has also been widely investigated, although diverse and contradictory patterns of relationships have been reported. Recent evidence suggests increased prevalence of mood and anxiety disorders among individuals who are overweight or obese compared to those with weight in the normal range (Simon et al., 2006), but the findings differ by type and severity of mental illness and by sex and age (Jorm et al., 2003; Larsson et al., 2002; McLaren et al., 2008). Research has suffered further due to the divergent definitions of mental health used across studies, and the subsequent diverse methods employed to measure it. However, it is generally accepted that the association between atypical body weight and mental disorders is multi-factoral and multi-level, with factors acting at cellular, intrapsychic, behavioural and social levels (McLaren et al., 2008). It is not yet clear whether the mental health associations of obesity necessarily manifest as psychiatric disorders, or on a sub-clinical level of distress.

Obesity (BMI $\geq 30$ ) is associated with mood disorders in community studies (Barry et al., 2008; Bruffaerts et al., 2008;
De Wit et al., 2010; Johnston et al., 2004; Luppino et al., 2010; Petry et al., 2008; Simon et al., 2006), although the relationship is affected by several confounding factors, especially gender. In women, depression is significantly associated with BMI, but in men it often is not (De Wit et al., 2010; Jorm et al., 2003; Lim et al., 2008; McLaren et al., 2008). Overweight (BMI between 25 and 29.9) is only sometimes associated with mood disorders, and then only in women (Barry et al, 2008; Petry et al., 2008).

Obesity is associated with anxiety disorders in community studies (Barry et al., 2008; Simon et al., 2006), and with anxiety disorders among women (but not men) (Jorm et al., 2003), while overweight is associated with some anxiety disorders (Petry et al., 2008).

Epidemiologic studies of alcohol consumption and body weight renders inconsistent results (Breslow \& Smothers, 2005). Some studies report positive associations between overweight and some substance use disorders (Petry et al., 2008), also influenced by age and gender (Barry \& Petry, 2009; McLaren et al., 2008), with recent research showing that it is drinking patterns, not volume, that is associated with BMI (Breslow \& Smothers, 2005). Other studies report significant inverse relationships between BMI and alcohol consumption: more obese patients consume less alcohol (John et al., 2005; Kleiner et al., 2004; Simon et al., 2006).

Among men, the risk of death from suicide is strongly inversely related to BMI, with the relationship remaining consistent after adjustment for medical illness, dietary factors, antidepressant use, physical activity, and social support (Magnusson et al., 2006; Mukamal et al., 2007).

The relationship between BMI, mental health, and chronic conditions is not clear. Increased BMI is associated with decreased physical well-being, but not with decreased emotional well-being on mental health measures (e.g. SF-36) (Doll et al., 2000; Katz et al., 2000). Obesity is associated with decreased 
emotional health in patients with other chronic conditions in adulthood (Doll et al., 2000) and adolescence (Renman et al., 1999). In some studies controlling for physical ill health alone accounted for the association of obesity with anxiety and depression in women (Jorm et al., 2003), which is consistent with hypothesis of physical ill health playing a mediating role (Jorm et al., 2003).

The above studies examined diagnostic disorders. Some studies found higher scores of sub-clinical conditions of anxiety and depression associated with increased BMI (Cilli et al., 2003; Jorm et al., 2003), while one found that overweight men were less likely to have sub-clinical symptoms of anxiety or depression compared to normal weight men and to women (McLaren et al., 2008). Previously, higher BMI scores were associated with higher Profile of Mood Scale, Short Form (POMS-SF) depression scores, and this association was retained after controlling for social desirability (Lim et al., 2008), although again differing per gender. BMI was related to depressive symptoms in women, but not in men (Lim et al., 2008). Higher BMI was associated with lower vitality (Yancy et al., 2002), and increased sub-clinical fatigue, as measured by the POMS-SF fatigue scale (Lim et al., 2008).

\section{Rationale}

The studies on the relationship between BMI and mental health were generally done on western or industrialised societies. African societies differ in their BMI profiles (Puane et al., 2002) and mental health presentation (Stein et al., 2008), which leads to the question whether the associations described elsewhere would hold true for SA samples.

There is a further question whether measures of transient mood states (like the POMS-SF described above) could be meaningfully associated with more stable anthropometric measures like BMI.

A convenient sample was located to investigate these issues. The SA armed forces requires all their members to undergo an annual occupational health assessment, at which time a BMI score is calculated, as well as a psychological screening completed. Members with known psychiatric diagnoses and known chronic conditions do not participate in the annual assessment, but follow a separate therapeutic management route. Participating members thus have no known mental health diagnosis, and no known chronic conditions. However, as found among the general population, they have high levels of overweight, with about $16 \%$ of women and $18 \%$ of men in the obese category (Van Wijk \& Van der Spuy, 2010). As their BMI will not have any relationship with psychiatric diagnoses, it allows for exploring the question whether it will be associated with levels of psychological distress, measured through sub-clinical or non-diagnostic mood-states.

\section{Methodology}

The convenience sample was drawn from active duty personnel, and ethics approval for the study was obtained from the Surgeon General's Ethics Committee. Recording of BMI scores and demographical data was done as part of the participants' annual occupational health surveillance. Participants signed an informed consent form, which indicated their willingness to allow their data to be used in the study.

\section{Study Population}

Individuals reporting for their annual occupational health surveillance were invited to participate in the study. At that time their BMI was noted, and age, gender, and race were also recorded. Previous research among the same population found that three factors predict BMI, namely age, race, and gender (Van Wijk \& Van der Spuy, 2010), which prompted its inclusion in the study.

\section{Instruments}

1) Anthropometric measurement. Participants were measured while wearing light clothes without shoes, jackets, or caps. Measurements were done on a Secca scale, and took place under the supervision of a dietician. The scale's automatic BMI calculation feature was used, while height had to be entered manually, and was rounded to the nearest centimetre for this purpose.

BMI was computed as weight (in kilograms) divided by the square of the height (in meters). The following WHO categories were used (CDC, 2010): underweight (BMI < 18.5), healthy weight (BMI 18.5 to 24.9), overweight (BMI 25.0 to $29.9)$, and obese (BMI $\geq 30.0)$.

2) Brunel Mood Scale. The Brunel Mood Scale (BRUMS) (Terry et al., 2003) is a short version of the Profile of Mood Scales (McNair et al., 1992), a widely used measure to assess transient affective mood states (McNair et al., 2003). It has proved an excellent measure of current mood states and their fluctuations in psychiatric outpatients, medical patients, normal adults, college students, and many other groups (McNair et al., 2003).

Developed on the basis of a series of factor-analytic studies, six factor based subscales were derived: Tension, Depression, Anger, Vigour, Fatigue, and Confusion (McNair et al., 1992). Good internal consistency, concurrent and criterion validity, and test-retest reliability has been reported for the POMS (McNair et al., 1992) and more recently for the BRUMS (Terry et al., 1999, 2003).

The 24-item BRUMS measures these six identifiable mood states through a self-report inventory, with respondents rating a list of adjectives. Patients usually respond to a 5-point Likert scale on the basis of how they had been feeling the previous week. The BRUMS has been used in studies investigating among others mood in sport and exercise (Lane et al., 2005; Lowther \& Lane, 2002), weight loss (Caulfield \& Karageorghis, 2008), the effect of hormones on mood (Coutts et al., 2006), and sleep profiles (Pedlar et al., 2006).

The six affective mood states subscales are not diagnostic indicators, but refer to sub-clinical psychological states. Using a formula, a total mood distress (TMD) score can be calculated from the six subscales.

\section{Procedure}

All the participants underwent anthropometric measurement as part of their health screening, which included height and weight, at which time a BMI score was calculated. They also underwent psychometric screening, where the BRUMS was included. Biographical data (i.e. age, race, gender) was also recorded as part of this screening. All the measurements were 
done on the same day.

\section{Analysis}

All recorded data was entered into the database anonymously. Statistical analysis used the Statistica 7 software program. The composition of the sample was analysed using descriptive statistics, while the relationship between BMI and BRUMS scores were explored using correlational statistics and ANOVA/ MANOVA.

\section{Results}

The demographic composition of the sample is described in Table 1. The sample consisted of 1621 participants, with 442 women $(27.3 \%)$ and 1179 men $(72.7 \%)$. Their ages ranged from 18 to 54 . The weight profile of the sample is represented in Table 2. The mean BMI for women was $28.2( \pm 4.3)$, and for men was $27.9( \pm 4.7)$. In summary, $55.4 \%$ of women and $55.8 \%$ of men in the sample were overweight $(\mathrm{BMI}>25)$. There were no significant difference between the BMI scores of women and men, but BMI did show a significant positive correlation with age $(\mathrm{r}=0.38, p<0.01)$. Both Black women and men had significantly lower mean BMI scores than White women and men respectively $(p<0.05)$.

In terms of mood states, age had no effect on BRUMS scores, but women consistently scored significantly more in the direction of negative moods on all subscales and TMD $(p<0.01)$. Race had no interaction with any of the BRUMS scores.

When considering the interaction between BMI and BRUMS scores of the total group, none of the 6 BRUMS subscales or the TMD showed any significant correlation with BMI scores. The women only sub-sample showed a small but significant negative correlation between BMI and Vigour $(r=-0.12, p<$ 0.05 ), while the men only sub-sample showed a small but significant negative correlation between BMI and Depression $(\mathrm{r}=$ $-0.07, p<0.05)$ and Confusion $(r=-0.07, p<0.05)$.

When age category was controlled, women's significant correlation with vigour was not maintained, nor men's significant correlation with confusion. Only men's negative correlation with depression remained significant.

\section{Discussion}

In contrast to previous studies (Cilli et al., 2003; Jorm et al.,

Table 1 .

Demographic characteristics of the sample.

\begin{tabular}{llllll}
\hline & & Women & \multicolumn{3}{l}{ Men } \\
\hline \multirow{4}{*}{ Age } & & $\mathrm{N}$ & $\%$ & $\mathrm{~N}$ & $\%$ \\
& $18-24$ & 195 & 44.1 & 390 & 33.1 \\
& $25-34$ & 178 & 40.3 & 428 & 36.3 \\
& $35-44$ & 53 & 12.0 & 211 & 17.9 \\
\multirow{4}{*}{ Race } & $45-54$ & 16 & 3.6 & 150 & 12.7 \\
& Black & 229 & 51.8 & 581 & 49.3 \\
& Coloured & 106 & 24.0 & 312 & 26.5 \\
\hline
\end{tabular}

\begin{tabular}{llllll}
\hline & Indian & 19 & 4.3 & 48 & 4.1 \\
& White & 88 & 19.9 & 238 & 20.2 \\
\hline $\begin{array}{l}\text { Table 2. } \\
\text { Weight per categories per gender. }\end{array}$ \\
\hline \multicolumn{5}{c}{ Women } & \multicolumn{3}{l}{ Men } \\
\hline Underweight & $\mathrm{N}$ & $\%$ & $\mathrm{~N}$ & $\%$ \\
Healthy weight & 5 & 1.1 & 5 & 0.4 \\
Overweight & 192 & 43.4 & 516 & 43.8 \\
Obese & 171 & 38.7 & 452 & 38.3 \\
\hline
\end{tabular}

2003; Lim et al., 2008), BMI was not associated with subclinical mood states. The only significant finding was that higher BMI was related to lesser depressed feelings in the male group. This seems to give some support to previous findings (McLaren et al., 2008) that overweight men are less likely to have sub-clinical symptoms of depression than normal weight men.

The composition of this sample may help explain the lack of meaningful associations. Firstly, it was a healthy sample, with all known psychiatric disorders excluded. This is not representative of a population-based sample, and thus differs from the previous studies cited above. Further, the sample is based in the armed forces, where severe obesity is considered 'unfit for duty', thus excluding most morbidly obese individuals.

Secondly, the BMI scores, as well as the BRUMS scores, seem to be closely concentrated around their respective means, and the small range would have restricted the scope for meaningful correlations.

Thirdly, the role of social desirability in response patterns have previously been implicated (Lim et al., 2008), and this study was conducted during participants' occupational health surveillance, which may have influenced responses. This was not controlled for, and should be included in future studies using self-report measures of subjective mood.

This study asked two questions. Firstly, would the association between body weight and mental health described elsewhere hold true for SA samples? The results suggest that those associations might not be directly transferable to SA samples. It could thus be hypothesised that the expression of BMI associated non-clinical psychological distress is different in African samples than those of industrialised societies. Further research is necessary to explore this possibility.

Secondly, can the BRUMS scores be meaningfully associated with BMI scores? Mood states, as measured by the BRUMS, reflects transient affective states, and is thus open to temporal influences. In contrast, anthropometric conditions, as measured by BMI scores, are relatively stable over time. In spite of previous success using the closely related POMS-SF, measures of transient mental states like the BRUMS may not be the most appropriate tools for use in correlation studies with stable constructs such as BMI.

Future studies investigating mental health associations with BMI need to include a wider range of both mental health and body weight, in order to determine whether the SA population 
exhibits the same trends as industrialised societies. Further, given the prevalence of excessive alcohol consumption in the military (Bray et al., 2003; Fear et al., 2007), and the suggestion that higher BMI may be due to excessive calorie intake through alcohol consumption (Breslow \& Smothers, 2005; McLaren et al., 2008), future studies need to investigate possible associations between BMI and substance use/abuse.

In conclusion, measures of transient mood states, like the BRUMS, may not be particularly useful in investigating relationships between mental health constructs and anthropometric measures, like BMI. At the same time, BMI does not appear to influence mood states in any meaningful way.

\section{References}

Barry, D., \& Petry, N. M. (2009). Associations between body mass index and substance use disorders differ by gender: Results from the National Epidemiologic Survey on Alcohol and Related Conditions. Addictive Behaviours, 34, 51-60. doi:10.1016/j.addbeh.2008.08.008

Barry, D., Pietrzak, R. H., \& Petry, N. M. (2008). Gender differences in associations between Body Mass Index and DSM-IV Mood and Anxiety Disorders: Results from the National Epidemiologic Survey on Alcohol and Related Conditions. Annals of Epidemiology, 18, 458-466. doi:10.1016/j.annepidem.2007.12.009

Bray, R. M., Hourani, L. L., Rae, K. L., Dever, J., \& Brown, A. (2003). Department of defense survey of health related behaviors among military personnel. Research Triangle Park, NC.: Research Triangle Institute.

Breslow, R. A., \& Smothers, B. A. (2005). Drinking Patterns and Body Mass Index in never smokers. American Journal of Epidemiology, 161, 368-376. doi:10.1093/aje/kwi061

Bruffaerts, R., Demyttenaere, K., Vilagut, G., Martinez, M., Bonnewyn, A., De Graaf, R., Haro, J.M., Bernert, S., Angermeyer, M. C., Brugha, T., Roick, C., \& Alonso, J. (2008). The relation between body mass index, mental health, and functional disability: A European population perspective. Canadian Journal of Psychiatry, 53, 679-688. doi:10.1080/02640410701837349

Caulfield, M. J., \& Karageorghis, C. I. (2008). Psychological effects of rapid weight loss and attitudes towards eating among professional jockeys. Journal of Sports Sciences, 26, 877-883.

Centers for Disease Control and Prevention (2001). About BMI for adults. Retrieved April 27, 2011.

http://www.cdc.gov/healthyweight/assessing/bmi/adult_BMI/index.h tml

Cilli, M., De Rosa, R., Pandolfi, C., Vacca, K., Cugini, P., Ceni, Z. H., $\&$ Bella, S. (2003). Quantification of sub-clinical anxiety and depression in essentially obese patients and normal weight health subjects. Eating and Weight Disorders, 8, 319-320.

Coutts, R. A., Rogerson, S., Deakin, G. B., Marshall-Gradinsnik, S. M., Meir, R. A., \& Zhou, S. (2006). Effect of short-term use of testosterone enanthate on personality and mood in healthy young males. Medicine \& Science in Sports \& Exercise, 38, 409. doi:10.1249/00005768-200605001-01725

De Wit, L., Luppino, F., Van Straten, A., Penninx, B., Zitman, F., \& Cuijpers, P. (2010). Depression and obesity: A meta-analysis of community-based studies. Psychiatry Research, 178, 230-235. doi:10.1016/j.psychres.2009.04.015

Doll, H. A., Petersen, S. E. K., \& Stewart-Brown, S. L. (2000). Obesity and Physical and Emotional Well-Being: Associations between body mass index, chronic illness, and the physical and mental components of the SF-36 questionnaire. Obesity Research, 8, 160-170. doi:10.1038/oby.2000.17

Fear, N. T., Iversen, A., Meltzer, H., Workman, L., Hull L., \& Greenberg, N. (2007). Patterns of drinking in the UK Armed Forces. Addiction, 102, 1749-1759. doi:10.1111/j.1360-0443.2007.01978.x

John, U., Meyer, C., Rumpf, H., \& Hapke, U. (2005). Relationships of psychiatric disorders with overweight and obesity in an adult general population. Obesity Research, 13, 101-109. doi:10.1038/oby.2005.13 Johnston, E., Johnston, S., McLeod, P., \& Johnston, M. (2004). The relation of body mass index to depressive symptoms. Canadian Journal of Public Health, 95, 179-183.

Jorm, A. F., Korten, A. E., Christensen, H., Jacomb, P. A., Ridgers, B., \& Parslow, R. A. (2003). Association of obesity with anxiety, depression, and emotional well-being: A community survey. Australian and New Zealand Journal of Public Health, 27, 434-440. doi:10.1111/j.1467-842X.2003.tb00423.x

Joubert, J., Norman, R., Bradshaw, D., Goedecke, J. H., Steyn, N. P., \& Puoane, T. (2007). Estimating the burden of disease attributable to excess body weight in South Africa in 2000. South African Medical Journal, 97, 683-690.

Katz, D. A., McHorney, C. A., \& Atkinson, R. L. Impact of obesity on health-related quality of life in patients with chronic illness. Journal of General Internal Medicine, 15, 789-796. doi:10.1046/j.1525-1497.2000.90906.x

Kleiner, K. D., Gold, M. S., Frostpineda, K., Lenzbrunsma, B., Perri, M. G., \& Jacobs, W. S. (2004). Body Mass Index and Alcohol Use. Journal of Addictive Diseases, 23, 105-118. doi:10.1300/J069v23n03 08

Kruger, H. S., Venter, C. S., \& Vorster, H. H. (2001). Obesity in African women in the North-West Province, South Africa is associated with an increased risk of non-communicable diseases: The THUSA study. Transition and health during urbanisation of South Africans. British Journal of Nutrition, 86, 733-740. doi:10.1079/BJN2001469

Lane, A. M., Jackson, A., \& Terry, P. C. (2005). Preferred modality influences on exercise induced mood changes. Journal of Sports Science and Medicine, 4, 195-200.

Larsson, U., Karlsson, J., \& Sullivan, M. (2002). Impact of overweight and obesity on health-related quality of life - A Swedish population study. International Journal of Obesity, 26, 417-424. doi:10.1038/sj.ijo.0801919

Levitt, N. S., Katzenellenbogen, J. M., Bradshaw, D., Hoffman, M. N., \& Bonnici, F. (1993). The prevalence and identification of risk factors for NIDDM in urban Africans in Cape Town, South Africa. Diabetes Care, 16, 601-607. doi:10.2337/diacare.16.4.601

Lim, W., Thomas, K. S., Bardwell, W. A., \& Dimsdale, J. E. (2008). Which measures of obesity are related to depressive symptoms and in whom? Psychosomatics, 49, 23-28. doi:10.1176/appi.psy.49.1.23

Lowther, J., \& Lane, A. (2002). Relationships between mood, cohesion and satisfaction with performance among soccer players. The Online Journal of Sport Psychology, 4.

Luppino, F. S., De Wit, L. M., Bouvy, P. F., Stijnen, T., Cuijpers, P., Penninx, B. W. J. H., \& Zitman, F. G. (2010). Overweight, Obesity, and Depression: A Systematic Review and Meta-analysis of Longitudinal Studies. Archives of General Psychiatry, 67, 220-229. doi:10.1001/archgenpsychiatry.2010.2

Magnusson, P. K., Rasmussen, F., Lawlor, D. A., Tynelius, P., \& Gunnell, D. (2006). Association of body mass index with suicide mortality: a prospective cohort study of more than one million men. American Journal of Epidemiology, 163, 1-8. doi:10.1093/aje/kwj002

McLaren, L., Beck, C.A., Patten, S. B., Fick, G. H., \&Adair, C. E. (2008). The relationship between body mass index and mental health: A population-based study of the effects of the definition of mental health. Social Psychiatry and Psychiatric Epidemiology, 43, 63-71. doi:10.1007/s00127-007-0269-x

Mukamal, K. J., Kawachi, I., Miller, M., \& Rimm, E. B. (2007). Body mass index and risk of suicide among men. Archives of Internal Medicine, 167, 468-75. doi:10.1001/archinte.167.5.468

McNair, D. M., Lorr, M., \& Droppleman, L. F. (1992). Revised manual for the Profile of Mood States. San Diego, CA: Educational and Industrial Testing Services.

McNair, D. M., Heuchert, J. W. P., \& Shilony, E. (2003). Profile of Mood States manual: Bibliography 1964-2002. New York: MultiHealth Systems Inc.

National Institutes of Health (1998). Clinical guidelines on the identi- 
fication, evaluation, and treatment of overweight and obesity in adults. Retrieved 27 April 2011.

http://www.nhlbi.nih.gov/guidelines/obesity/ob_home.htm

Pedlar, C. R., Lane, A. M., Lloyd, J. C., Dawson, J., Emegbo, S., \& Whyte, G. P. (2006). Sleep profiles and mood states during an expedition to the South Pole. Wilderness and Environmental Medicine, 18, 127-132. doi:10.1580/06-WEME-BR-039R1.1

Petry, N. M., Barry, D., Pietrzak, R. H., \& Wagner, J. A. (2008). Overweight and obesity are associated with psychiatric disorders: Results from the National Epidemiologic Survey on Alcohol and related conditions. Psychosomatic Medicine, 70, 288-297. doi:10.1097/PSY.0b013e3181651651

Puoane, T., Steyn, K., Bradshaw, D., Laubscher, R., Fourie, J., Lambert, V., \& Mbananga, N. (2002). Obesity in South Africa: The South African demographic and health survey. Obesity Research, 10, 1038-1048. doi:10.1038/oby.2002.141

Simon, G. E., Von Korff, M., Saunders, K., Miglioretti, D. L., Crane, P. K., van Belle, G., \& Kessler, R. C. (2006). Association between obesity and psychiatric disorders in the US adult population. Archives of General Psychiatry, 63, 824-830. doi:10.1001/archpsyc.63.7.824

Stein, D. J., Seedat, S., Herman, A., Moomal, H., Heeringa, S. G., Kessler, R. C., \& Williams, D. R. (2008). Lifetime prevalence of psychiatric disorders in South Africa. British Journal of Psychiatry, 192, 112-117. doi:10.1192/bjp.bp.106.029280

Steyn, K., Fourie, J. M., Lombard, C. J., Katzenellenbogen, J., Bourne, L. T., \& Jooste, P. L. (1996). Hypertension in the black community of the Cape Peninsula: The BRISK study. East African Medical Journal, 73, 756-760.

Terry, P. C., Lane, A. M., \& Fogarty, G. J. (2003). Construct validity of the POMS-A for use with adults. Psychology of Sport and Exercise, 4, 125-139. doi:10.1016/S1469-0292(01)00035-8

Terry, P. C., Lane, A. M., Lane, H. J., \& Keohane, L. (1999). Development and validation of a mood measure for adolescents. Journal of Sports Sciences, 17, 861-872. doi:10.1080/026404199365425

Van Wijk, C. H., \& Van der Spuy, A. (2010). Relationship between BMI and demographic variables in the SA Navy. Technical Report, Simon's Town: Institute for Maritime Medicine.

World Health Organization (1995). Physical status: The use and interpretation of anthropometry. WHO Technical Report Series. Geneva: World Health Organization.

Yancy, W. S., Olsen, M. K., Westman, E. C., Bosworth, H. B., \& Edelman, D. (2002). Relationship between obesity and health-related quality of life in men. Obesity Research, 10, 1057-1064. doi:10.1038/oby.2002.143 